
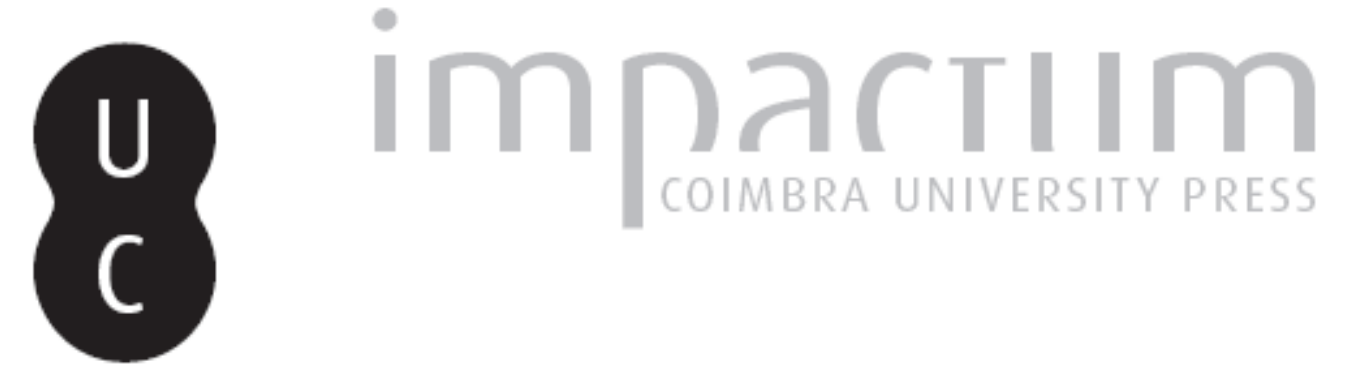

\title{
O porto de Ponta Delgada, S. Miguel, Açores: avaliação das consequências de galgamento pelo método AHP
}

\author{
Autor(es): $\quad$ Rodrigues, Joana; Fortes, Conceição Juana; Reis, Maria Teresa; \\ Poseiro, Pedro; Pinto, Francisco Taveira \\ Publicado por: $\begin{aligned} & \text { Associação Portuguesa de Riscos, Prevenção e Segurança; Imprensa } \\ & \text { da Universidade de Coimbra }\end{aligned}$ \\ URL \\ persistente: \\ URI:http://hdl.handle.net/10316.2/41229 \\ DOI: \\ DOI:https://doi.org/10.14195/1647-7723_24_9
}

Accessed : $\quad$ 26-Apr-2023 14:01:55

A navegação consulta e descarregamento dos títulos inseridos nas Bibliotecas Digitais UC Digitalis, UC Pombalina e UC Impactum, pressupõem a aceitação plena e sem reservas dos Termos e Condições de Uso destas Bibliotecas Digitais, disponíveis em https://digitalis.uc.pt/pt-pt/termos.

Conforme exposto nos referidos Termos e Condições de Uso, o descarregamento de títulos de acesso restrito requer uma licença válida de autorização devendo o utilizador aceder ao(s) documento(s) a partir de um endereço de IP da instituição detentora da supramencionada licença.

Ao utilizador é apenas permitido o descarregamento para uso pessoal, pelo que o emprego do(s) título(s) descarregado(s) para outro fim, designadamente comercial, carece de autorização do respetivo autor ou editor da obra.

Na medida em que todas as obras da UC Digitalis se encontram protegidas pelo Código do Direito de Autor e Direitos Conexos e demais legislação aplicável, toda a cópia, parcial ou total, deste documento, nos casos em que é legalmente admitida, deverá conter ou fazer-se acompanhar por este aviso.

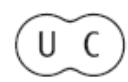




\section{MULTIDISCIPLINARIDADE NA ANÁLISE DAS MANIFESTAÇÕES DE RISCO}

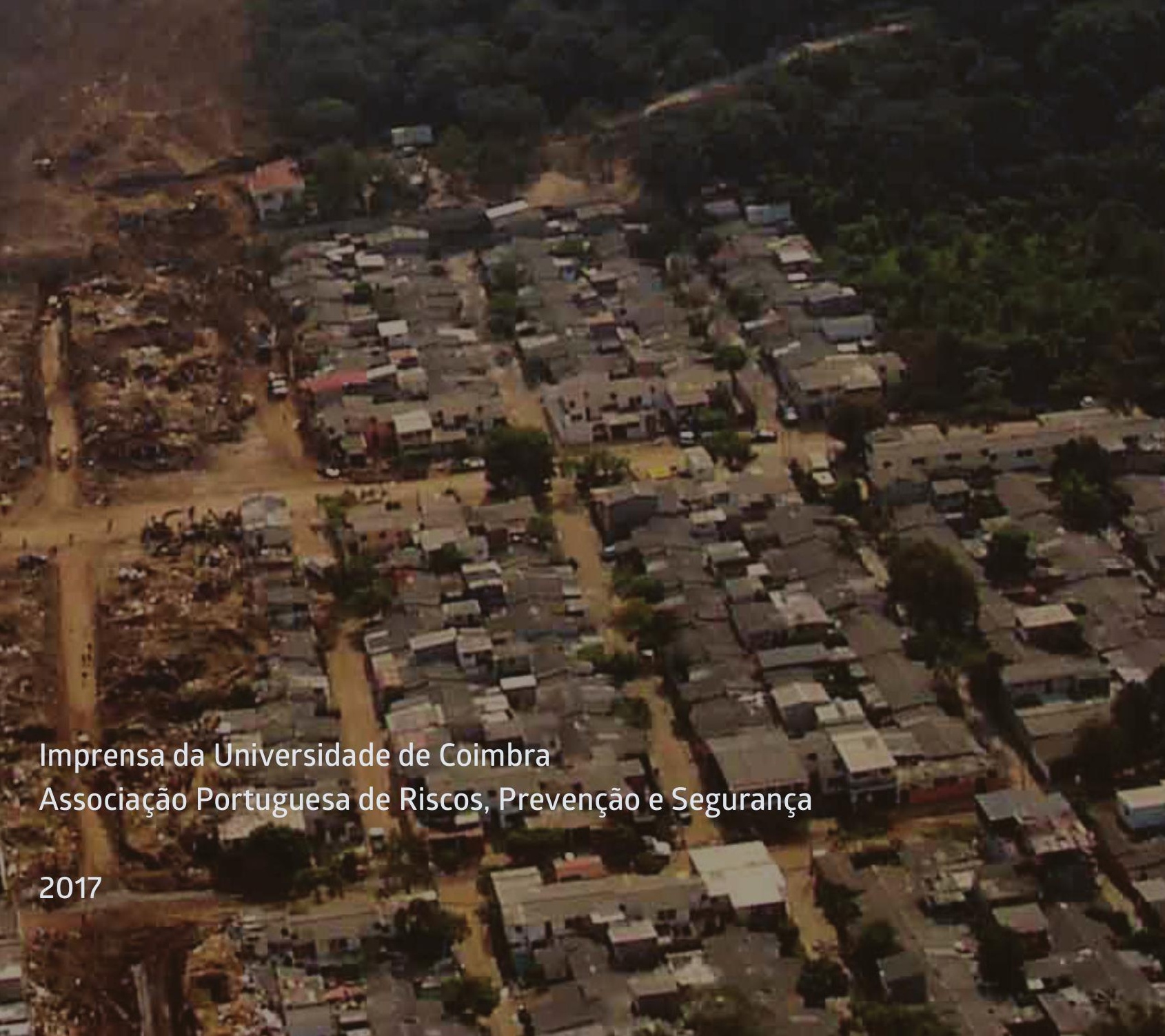




\section{O PORTO DE PONTA DELGADA, S. MIGUEL, AÇORES: AVALIAÇÃO DAS CONSEQUÊNCIAS DE GALGAMENTO PELO MÉTODO AHP* \\ PORT OF PONTA DELGADA, S. MIGUEL, AZORES: \\ ASSESSMENT OF THE CONSEQUENCES OF OVERTOPPING USING AHP METHODOLOGY}

\author{
Joana Rodrigues \\ Faculdade de Engenharia da Universidade do Porto \\ ec09154@fe.up.pt \\ Conceição Juana Fortes \\ Laboratório Nacional de Engenharia Civil \\ jfortes@lnec.pt
}

Maria Teresa Reis

Laboratório Nacional de Engenharia Civil treis@lnec.pt

Pedro Poseiro

Laboratório Nacional de Engenharia Civil pposeiro@lnec.pt

Francisco Taveira Pinto

Faculdade de Engenharia da Universidade do Porto fpinto@fe.up.pt

\section{RESUMO}

No presente trabalho descreve-se a aplicação de uma metodologia para avaliação das consequências do galgamento no porto de Ponta Delgada, S. Miguel, Açores, recorrendo a uma análise multicritério (Processo de Análise Hierárquica, AHP) do impacto da ocorrência de galgamentos superiores aos limites admissíveis. Esta metodologia permite obter resultados baseados numa análise espacial dos indicadores que caraterizam a zona portuária em estudo, no que diz respeito à sua importância relativa.

Palavras-chave: Consequências, galgamento, análise multicritério (AHP), portos, Ponta Delgada.

\section{ABSTRACT}

This work describes the application of a methodology for assessment of overtopping consequences at the port of Ponta Delgada, S. Miguel, Azores, by using a multi-criteria analysis (Analytic Hierarchy Process, AHP) on the impact of extreme overtopping exceeding the admissible values. Such approach allows obtaining results based on spatial analysis of the indicators that characterize the studied port area with respect to their relative importance.

Keywords: Consequences, wave overtopping, multi-criteria analysis (AHP), ports, Ponta Delgada.

\section{RESUMEN}

Puerto de Ponta Delgada, S. Miguel, Azores: Evaluación de las Consecuencias de Rebase Utilizando la Metodología $A H P$ - En el presente trabajo se describe la aplicación de una metodología d' evaluación de consecuencias de rebase al puerto de Ponta Delgada, S. Miguel, Azores, recurriendo a un análisis de criterio múltiple (Proceso de Análisis Jerárquico, AHP) del impacto de la ocurrencia de un nivel de rebase superior a los limites admisibles. Esta metodología permite obtener resultados basados en el análisis espacial de los indicadores que caracterizan la zona portuaria en estudio con respecto a su importancia relativa.

Palabras clave: Consecuencias, rebase, análisis de criterio múltiple (AHP), puertos, Ponta Delgada.

\section{RESUMÉ}

Port de Ponta Delgada, S. Miguel, Açores: Evaluation des conséquences de de surexploitation selon la méthode AHP - Le présent travail décrit l'application d'une méthodologie d'évaluation des conséquences de la surexploitation du port de Ponta Delgada, S. Miguel, aux Açores, en utilisant une analyse multicritères (Analyse Hiérarchique des Procédés, AHP) sur l'impact des dépassements extrêmes supérieur aux valeurs admissibles. Une telle approche permet d'obtenir des résultats basés sur l'analyse spatiale des indicateurs qui caractérisent la zone portuaire étudiée en tenant compte de leur importance relative.

Mots-clé: Conséquences, surexploitation, analyse multicritère (AHP), ports, Ponta Delgada.

* O texto deste artigo corresponde a uma comunicação apresentado no III Congresso Internacional, I Simpósio Ibero-Americano e VIII Encontro Nacional de Riscos, tendo sido submetido em 09-02-2014, sujeito a revisão por pares a 30-04-2015 e aceite para publicação em 28-03-2016.

Este artigo é parte integrante da Revista Territorium, $n .{ }^{\circ} 24,2017,{ }^{\circ}$ RIscos, ISSN: 0872-8941. 
Introdução

A importância do porto de Ponta Delgada (fig.1), ilha de S. Miguel, Açores, prende-se com o elevado fluxo de pessoas e mercadorias, bem como com as ligações que proporciona com as restantes ilhas do arquipélago, o continente e o resto do mundo.

Em situações de tempestade, a ocorrência de galgamentos no porto é muito frequente, principalmente na zona do molhe principal, devido à forte agitação marítima que se faz sentir naquelas situações. Note-se que, neste porto, a agitação se caracteriza por alturas significativas de onda que atingem valores de $7 \mathrm{~m}$, sendo que os períodos médios variam entre $0.46 \mathrm{~s}$ a $12.5 \mathrm{~s}$. Estes valores foram obtidos para o período de 25 de agosto de 2005 a 31 de dezembro de 2013, com base em dados de boia-ondógrafo (com coordenadas geográficas $37.726449^{\circ} \mathrm{N}$ e $25.720908^{\circ} \mathrm{W}$, e a profundidade da ordem dos $120 \mathrm{~m}$ ) utilizados no trabalho de J. Rodrigues (2014).

Segundo informação prestada pelas entidades portuárias, o molhe principal é o local onde se observam galgamentos com maior frequência e intensidade, atingindo todo o seu comprimento e tendo já havido a necessidade de uma obra de reforço da proteção do molhe devido à ocorrência do temporal de 1996. Contudo, não existe um levantamento sistemático de ocorrência de fenómenos de galgamento neste molhe. Estas entidades apenas referiram os galgamentos dos dias de tempestade de 27 de setembro de 2011, 22 de março de 2012 e 20 de agosto de 2012, por serem muito significativos e terem implicado a inoperacionalidade do porto. No entanto, acontecem com frequência galgamentos de menor dimensão, que não implicam a interrupção da operação portuária, mas aos quais podem estar associadas outras consequências.

Note-se que diversas atividades fundamentais para a economia das ilhas se desenrolam neste molhe. Com efeito, ao longo deste molhe, efetua-se o abastecimento

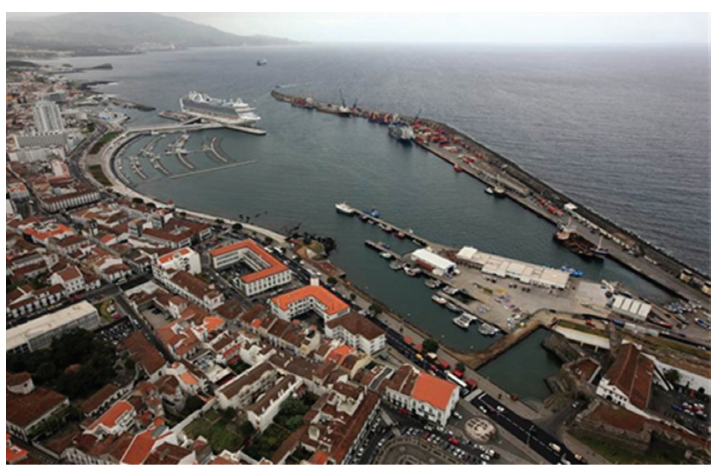

Fig. 1 - Fotografia aérea do porto de Ponta Delgada D. M. F. Silva et al., 2012).

Fig. 1 - Aerial view of Ponta Delgada harbour (D. M. F. Silva et al., 2012). de navios de água potável, combustível e gás natural, o funcionamento da alfândega e serviços do porto e a carga e descarga de mercadorias para distribuição às diversas ilhas. Tem uma grande área para contentores e vários armazéns integrados na superestrutura do molhe. Relativamente ao acesso pedonal, só é permitida a circulação de pessoas que trabalhem no próprio porto, tripulações de embarcações ou indivíduos autorizados. Os veículos de transporte de mercadorias e de tripulação são os únicos que podem circular nesta área.

Dada a importância das atividades associadas ao molhe e ao porto em geral, as consequências ao nível da operacionalidade portuária e da segurança de pessoas e bens (fig. 2 e fig. 3) são relevantes e, por conseguinte, a avaliação do risco de ocorrência de galgamentos para este porto é fundamental, de modo a dotar as entidades responsáveis locais da informação necessária para o planeamento e gestão desta zona.

Neste âmbito, os trabalhos de D. M. F. Silva (2012) e D. M. F. Pereira (2013) constituíram estudos pioneiros neste campo para o porto de Ponta Delgada, tendo aplicado metodologias para o cálculo do galgamento, para a análise das suas consequências e para a avaliação do risco (P. Poseiro et al., 2013a,b). Nesses trabalhos, foi efetuada uma avaliação do risco para cinco secções das estruturas do porto, para um período de dados de agitação marítima de 2 anos, nível de maré constante e utilizando uma metodologia simples de avaliação das consequências de ocorrência de galgamentos superiores aos limites admissíveis, que avaliava global e qualitativamente as consequências da sua ocorrência numa dada zona de estudo. Este trabalho foi estendido por J. Rodrigues (2014), com a avaliação do risco de
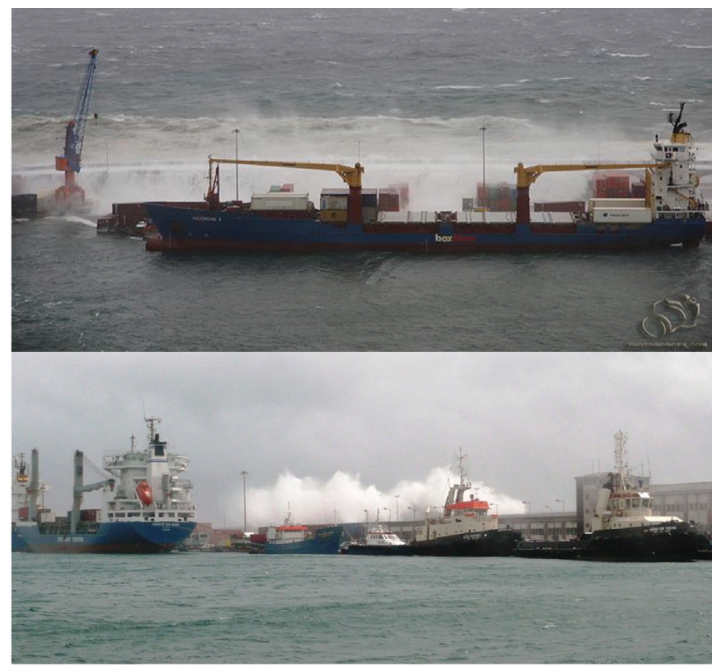

Fig. 2 - Fenómenos de galgamento no Porto de Ponta Delgada, Açores (Fonte: Google Earth e José Borges).

Fig. 2 - Overtopping events at Ponta Delgada harbour, Azores (Source: Google Earth and José Borges). 
galgamento para doze secções das estruturas do referido porto (fig. 4), considerando um período de dados de agitação marítima de 34 anos (1979 a 2013) e o nível de maré real.

Com efeito, em qualquer destas aplicações, a avaliação das consequências da ocorrência de galgamentos excessivos foi efetuada apenas com base em informação
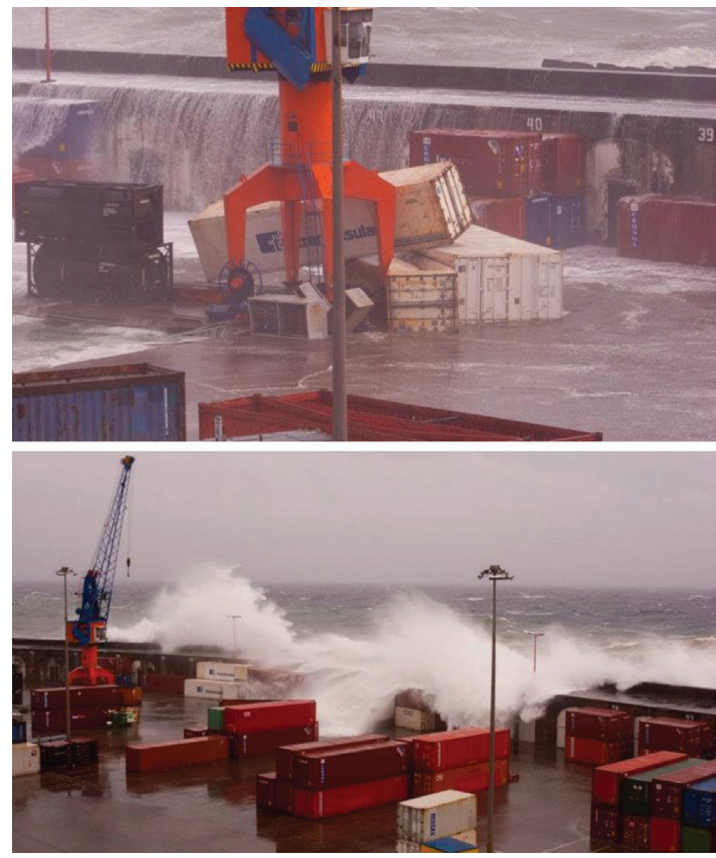

Fig. 3 - Galgamento no molhe principal do porto de Ponta Delgada em 2011 (Fotografias - Jimmy The Sailor).

Fig. 3 - Overtopping at the main breakwater of Ponta Delgada harbour, 2011 (Photos - Jimmy The Sailor). fornecida pelas autoridades responsáveis, avaliando-se global e qualitativamente essas consequências em cada uma das zonas consideradas. Teve-se em conta, apenas de forma indireta, indicadores que representam a distribuição espacial ou a existência de infraestruturas. Além disso, não houve a preocupação de atribuir pesos a esses indicadores que permitissem expressar a importância relativa de cada um deles para a zona em estudo, de modo a que o resultado final mostrasse o mapa de consequências tendo em conta simultaneamente todos os indicadores.

É, neste âmbito, que se insere o presente trabalho, no sentido de efetuar uma análise mais aprofundada, quantitativa e detalhada das consequências associadas à ocorrência de galgamentos excessivos para o porto de Ponta Delgada e construir, deste modo, um mapa das consequências. Para tal, utilizou-se uma metodologia baseada numa análise multicritério, que permite analisar, classificar e atribuir pesos a diferentes indicadores espaciais (por exemplo, a distribuição espacial da população, das infraestruturas marítimas e terrestres, do património construído, dos serviços e atividades na zona, ou a extensão da zona afetada pelo galgamento, expressa em termos de cotas de inundação) que caraterizam uma dada zona de estudo (O. Antunes, 2012; P. Poseiro et al., 2013b). Esta metodologia, para elaboração do mapa de consequências, consiste na construção de um índice espacial de pressão antrópica no litoral através da aplicação do Processo de Análise Hierárquica (AHP), dando continuidade ao trabalho já desenvolvido por, por exemplo, S. Carver (1991), J. Malczewsky (2006) e R. Greene et al. (2011) sobre a aplicação deste método conjuntamente com ferramentas SIG.

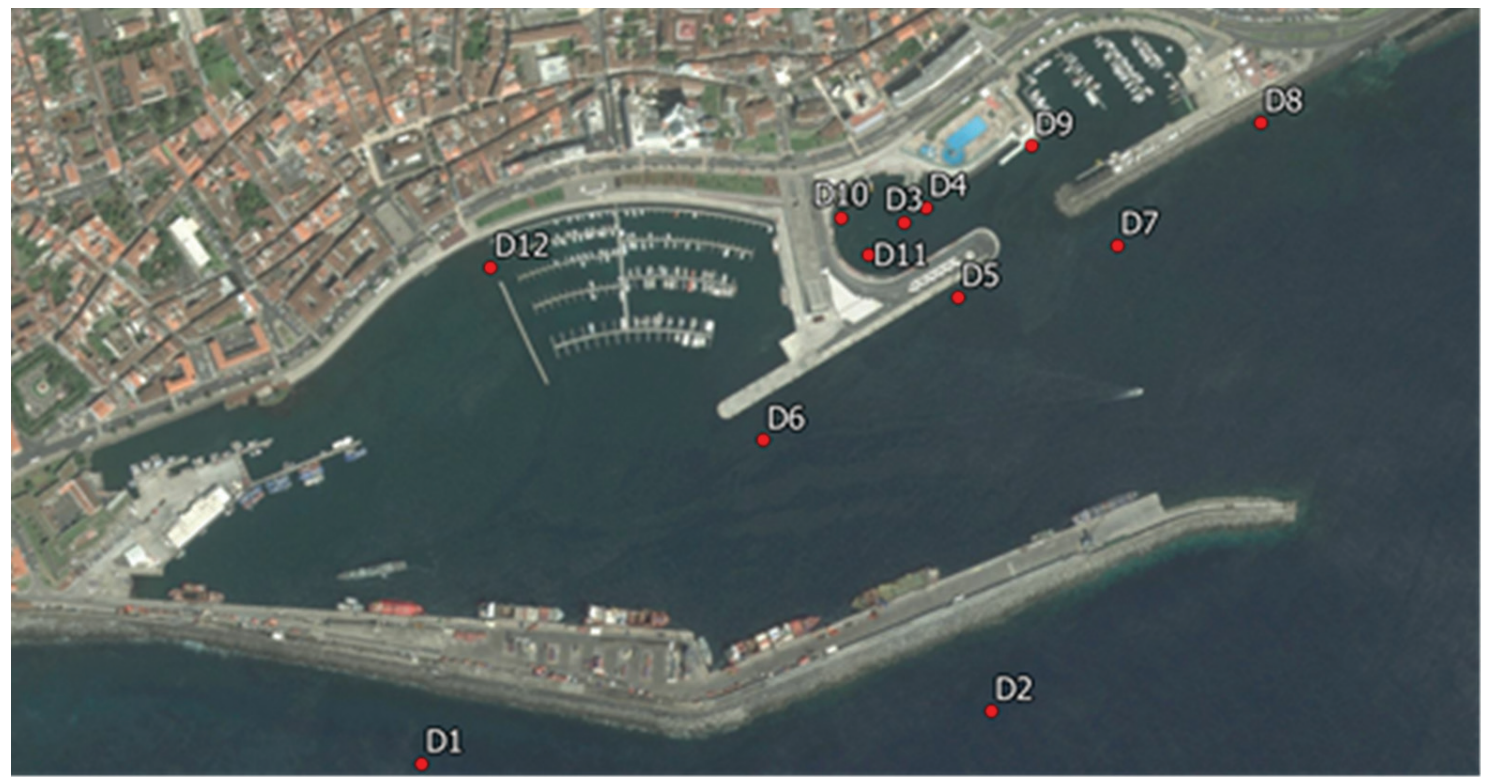

Fig. 4 - Estruturas selecionadas para avaliação das consequências (J. Rodrigues, 2014).

Fig. 4 - Structures selected for consequences evaluation (J. Rodrigues, 2014). 
Para tal, recorreu-se ao trabalho de O. Antunes (2012), no âmbito do projeto Regulações e Conflitos Ambientais devido à Erosão Costeira, promovido pelo LNEC e em parceria com a Universidade Nova de Lisboa. Este trabalho pretendeu quantificar a pressão antrópica, com base na presença e ação do Homem, bem como das dinâmicas naturais das zonas costeiras, através da localização geográfica das potenciais áreas críticas. Desta forma, este autor desenvolveu uma metodologia para construir um índice espacial de pressão antrópica no litoral português através da aplicação do AHP. O Processo de Análise Hierárquica baseia-se na comparação sucessiva e emparelhada da informação selecionada e quantificada, tendo em vista a sua priorização hierárquica atendendo à relevância estimada de cada critério ou indicador considerado (J. L. Craveiro et al., 2012), como ilustrado adiante.

Se bem que a inovação metodológica, já datada dos anos $70 / 80$ do século passado (T. Saaty, 1980), privilegiando a seleção de ações e investimentos alternativos, tenha tido um propósito de uso limitado ao setor empresarial, depressa a oportunidade metodológica oferecida, de se ponderarem decisões diferentes, alargou o campo da sua aplicação a outros contextos. Esses outros contextos de aplicação têm integrado a ponderação de decisões de ordem ambiental, e a compreensão de valores e atitudes por parte de stakeholders em processos de participação pública (P. Aragonés-Beltrás et al., 2015). Igualmente, em outro projeto em curso com elementos da equipa autora, a aplicação da AHP incide sobre a valorização de fatores de confiança ou incerteza face à adoção de novas tecnologias de produção de água para consumo humano, na região algarvia (M. J. Freitas e J. L. Craveiro, 2015). Deste modo, a metodologia AHP tem-se revelado uma metodologia robusta com várias possibilidades de aplicação, desde que estejam em causa valorizações diferenciadas entre opções ou condições alternativas de análise para a tomada de decisão. A AHP representa, pois, um instrumento rico em possibilidades de aplicação e abrangências temáticas, tendo sido utilizada no caso presente com os propósitos enunciados acima, e como um processo de seleção seriada sobre a pressão antrópica em zonas costeiras.

Neste processo foram considerados vários indicadores (e sub-indicadores) para representar a pressão antrópica, que incluíam a distribuição espacial do uso do solo, dos edifícios, da população e do turismo. A estes indicadores e sub-indicadores (no caso da população, por exemplo, consideraram-se dois sub-indicadores: Densidade populacional líquida e População total presente), atribuíram-se diferentes pesos, a partir da aplicação do AHP. Cada um destes indicadores foi integrado num sistema de informação geográfica (SIG) sob a forma de camada (layer), cada uma caracterizada por um conjunto de propriedades. Desta forma, fazem-se corresponder a cada uma dessas propriedades diferentes valores (pesos) numa escala que varia entre 1 e 9, correspondendo os valores maiores às propriedades do indicador mais importante. De notar que, em cada ponto do espaço, existirá apenas uma daquelas propriedades. Por fim, a ferramenta Weighted Overlay permitiu integrar todos os indicadores (e subindicadores) com os seus pesos definidos e assim obter o mapa de consequências.

O artigo consiste, então, na apresentação e aplicação desta metodologia na avaliação das consequências de ocorrência de galgamentos no porto de Ponta Delgada. A organização da informação relevante para o caso de estudo foi executada em várias fases. Começou-se por definir e organizar num sistema SIG (Sistema de Informação Geográfica) a informação mais importante para o estudo, sob a forma de níveis de informação (layers). Cada um desses níveis corresponde a um indicador. No caso do porto de Ponta Delgada, os indicadores considerados foram: Património Arquitetónico, Locais Especiais, Edificado, Altimetria, Rede Viária, Uso do Solo e População. Note-se que a escolha destes indicadores se baseou no facto de serem aqueles para os quais foi disponibilizada informação pelas entidades responsáveis, serem os considerados pelos autores como os mais relevantes para caraterizar o local e cujo impacto associado ao fenómeno do galgamento pode ser significativo. Depois, aplicou-se o método AHP para definir o peso a atribuir a cada indicador. Efetuou-se também a classificação dos atributos de cada indicador no sentido de também estes terem diferentes pesos. E por fim, tal como em O. Antunes (2012), utilizou-se a função Weighted Overlay, com vista à obtenção de um mapa com diferentes níveis de consequências. Para o tratamento e organização dos dados, utilizou-se a ferramenta ModelBuilder, disponível no ArcGISTM.

O objetivo final da aplicação desta metodologia mais complexa de avaliação das consequências de ocorrência de galgamentos excessivos é permitir futuramente realizar uma avaliação do risco mais realista, onde se cruza o mapa de probabilidade de ocorrência de galgamentos (com a distribuição espacial das áreas inundadas) e as caraterísticas espaciais do local em estudo, através do mapa de consequências.

Depois deste capítulo de introdução, é efetuada uma breve descrição da metodologia AHP. Segue-se a sua aplicação ao porto de Ponta Delgada e a construção do respetivo mapa de consequências.

\section{Metodologia}

A metodologia para avaliação das consequências aplicada neste artigo aproxima-se da apresentada em 0 . Antunes (2012) e P. Poseiro et al. (2013b). Esta metodologia consiste nos seguintes passos:

1. Recolha e organização dos indicadores num SIG;

2. Aplicação do Processo de Análise Hierárquica (AHP) aos indicadores; 
3. Classificação dos atributos de cada indicador;

4. Sobreposição ponderada dos indicadores no SIG de acordo com os pesos definidos (Weighted Overlay);

5. Implementação do processo na ferramenta ModelBuilder.

O processo de avaliação das consequências iniciase, assim, com a seleção dos indicadores espaciais considerados mais relevantes para a caraterização do local e que depois serão integrados num SIG.

Aos indicadores considerados aplica-se o AHP, que é normalmente aplicado para a tomada de decisão em diversos cenários complexos, em que indivíduos trabalham em conjunto para tomar decisões e onde perceções humanas, julgamentos e consequências possuem repercussões de longo prazo (N. Bhushan e R. Kanwal, 2004). Este processo permite a construção de um índice espacial em que são atribuídos diferentes pesos aos vários indicadores.

A comparação entre dois ou mais indicadores utilizando - AHP pode ser realizada de diferentes formas. No entanto, a escala de importância relativa entre duas alternativas, proposta por T. L. Saaty (2005), é a mais frequentemente utilizada. Saaty propõe uma escala de importância relativa entre pares de indicadores $(a, b)$ em que se indica qual o nível de importância do indicador ' $a$ ' face ao indicador ' $b$ '. Atribuem-se valores que variam entre 1 e 9 no caso de ' $a$ ' ser mais importante que ' $b$ ' ou o seu recíproco quando ' $b$ ' for mais importante que ' $a$ '. A matriz de comparação é construída como indicado na TABELA I para $\mathrm{n}$ indicadores.

Para obter os pesos relativos a cada indicador é necessário normalizar esta matriz. Para tal, para uma dada coluna, divide-se o valor de cada coeficiente pela soma de todos os coeficientes dessa coluna. Após normalizar esta matriz, a média aritmética dos valores obtidos em cada linha da matriz corresponde ao valor aproximado do vetor próprio, que por sua vez corresponde ao peso de cada indicador (R. V. Vargas, 2010).

Este processo apresenta características próprias que dão a garantia da consistência dos seus resultados. Para validar a consistência dos pesos atribuídos é calculado um índice de inconsistência $\left(l_{\text {Max }}\right)$, um índice de consistência (Cl) e uma taxa de consistência (CR), como mostram as equações 1,2 e 3, respetivamente:

$$
\begin{aligned}
& \lambda_{\text {Max }}=\Sigma\left(\text { Vetor próprio }{ }_{\text {Indicador } i} \times\right. \text { Peso total de cada } \\
& \text { coluna } \left._{\text {Indicador }}\right) \quad \mathrm{i}=1, \ldots, \mathrm{n} \\
& \mathrm{Cl}=\left(\lambda_{\text {Max }}-\mathrm{n}\right) /(\mathrm{n}-1) \\
& \mathrm{CR}=\mathrm{Cl} / \mathrm{RI}<0.1
\end{aligned}
$$

em que $\mathrm{n}$ representa o número de indicadores avaliados e RI o índice de consistência aleatória. A matriz será considerada consistente se $C R$ for menor do que 0.1 (10\%). O valor de RI é fixo para um dado número de indicadores avaliados, $\mathrm{n}$, conforme a TABELA II (genérica).

TABELA II - Valores do índice de consistência aleatória, RI, em função do número de indicadores considerados, $n$.

TABLE II - Random consistency index values, RI, as a function of the number of disaster criteria, $n$.

\begin{tabular}{|c|c|c|c|c|c|c|c|}
\hline $\mathrm{n}$ & 1 & 2 & 3 & 4 & 5 & 6 & 7 \\
\hline $\mathrm{RI}$ & 0 & 0 & 0.58 & 0.9 & 1.12 & 1.24 & 1.32 \\
\hline
\end{tabular}

Cada indicador é caraterizado por um conjunto de atributos espaciais (por exemplo, no indicador 'Uso do Solo', podem existir os seguintes atributos: solos naturais, solos urbanizados e solos de uso especial), a que também se tem de fazer corresponder diferentes pesos.

A finalização do processo dá-se com a sobreposição ponderada dos indicadores no SIG de acordo com os diferentes pesos definidos a partir do AHP (Weighted Overlay) e dos seus atributos, também com pesos diferentes, resultando assim num mapa de consequências.

Com o intuito de aplicar esta metodologia é criado um diagrama com a ferramenta ModelBuilder, disponibilizada no software comercial ArcGIS ${ }^{T M}$. Esta ferramenta permite criar um fluxograma que mostra as operações necessárias à obtenção do mapa de consequências, utilizando as ferramentas (Toolboxes) disponibilizadas por este software.

Este novo método de avaliação das consequências de ocorrência de galgamento apresenta inúmeras vantagens relativamente ao método mais expedito, na medida em

TABELA I - Matriz de comparação de $n$ indicadores segundo T. L. Saaty (2005).

TABLE I - Comparison matrix of disaster criteria according to T. L. Saaty (2005).

\begin{tabular}{|c|c|c|c|c|}
\hline & Indicador 1 & Indicador 2 & $\ldots$ & Indicador $\mathrm{n}$ \\
\hline Indicador 1 & 1 & Avaliação numérica & Avaliação numérica & Avaliação numérica \\
\hline Indicador 2 & 1 /Avaliação numérica & 1 & Avaliação numérica & Avaliação numérica \\
\hline$\ldots$ & 1/Avaliação numérica & 1/Avaliação numérica & 1 & Avaliação numérica \\
\hline Indicador $\mathbf{n}$ & 1/Avaliação numérica & 1/Avaliação numérica & 1 /Avaliação numérica & 1 \\
\hline
\end{tabular}


que da sua aplicação advêm resultados mais fiáveis e precisos. Isto deve-se às alterações implementadas em várias etapas:

- No método expedito (P. Poseiro et al., 2013a), a avaliação das consequências de galgamento é feita segundo graus que variam de 'insignificantes' a 'catastróficas'. No novo método, ao invés de serem utilizados meros indicadores que resultam apenas numa avaliação qualitativa do grau de consequências em cada ponto, faz-se agora uma distribuição espacial dos mesmos, permitindo obter um mapa de grau de consequências que tem em conta o peso de todos os indicadores em simultâneo.

- Além da análise feita aos indicadores, estes podem ser constituídos por vários atributos que os caracterizam espacialmente, sendo feita a atribuição de diferentes pesos a cada um desses atributos (segundo uma classificação que varia de 1 a 9), o que permite uma categorização mais pormenorizada de cada nível de informação conforme o seu grau de importância.

\section{Caso de Estudo}

\section{O porto de Ponta Delgada}

O porto de Ponta Delgada situa-se na costa sul da ilha de S. Miguel, Região Autónoma dos Açores, Portugal (fig. 5). É o principal porto dos Açores, construído na cidade mais populosa do arquipélago (cerca de $26 \%$ da população açoriana) e tem cerca de 32 ha de área de baía protegida pelo molhe principal sul (fig. 6). Apresenta um papel imprescindível no transporte de pessoas e mercadorias, não só no que diz respeito às ligações com as restantes ilhas do arquipélago, mas também com o continente e o resto do mundo. Encontra-se na rota turística transatlântica, permitindo receber ferryboats e cruzeiros turísticos. Ponta Delgada é atualmente o centro económico, administrativo e turístico dos Açores.

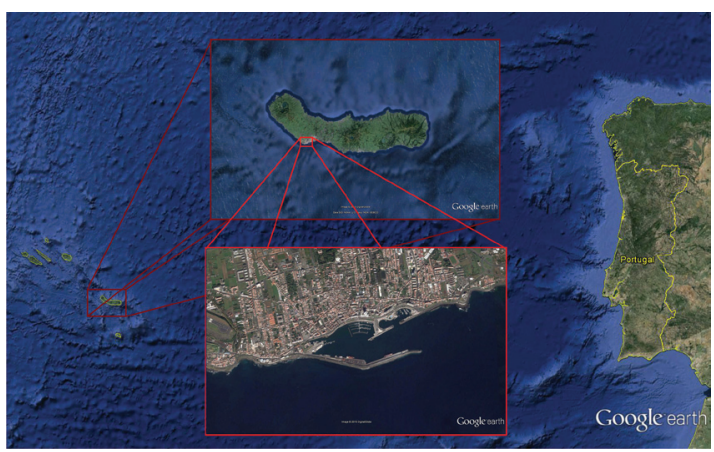

Fig. 5 - Localização geográfica do porto de Ponta Delgada (adaptado do Google Earth).

Fig. 5 - Location of Ponta Delgada harbour (adapted from Google Earth).
A construção deste porto artificial, datada de 1861, surgiu da necessidade de expandir as áreas de entrada e saída de pessoas e bens da ilha, tornando-o adequado a um grande movimento de navios. A 30 de setembro do referido ano iniciaram-se as obras de construção do porto artificial de Ponta Delgada, com recurso a pedra extraída das pedreiras de Santa Clara, sendo que estas obras se arrastaram até 1942 . No entanto, ainda durante a construção do molhe-cais inicial, ocorreu no ano de 1864 um temporal que obrigou à reavaliação do projeto inicial e à introdução de medidas corretivas consideradas mais convenientes na altura. Ainda nesse período de construção, no ano de 1894, registou-se um outro temporal, bastante mais violento, que destruiu $260 \mathrm{~m}$ do troço do molhe-cais entretanto já construído (fig. 7) e arremessou para o mar os cinco guindastes que aí eram utilizados. Finalizado o molhe-cais, este apresentava já uma estrutura bastante semelhante à atual, embora mais curto.

Durante os anos seguintes verificou-se a expansão do porto com várias obras de melhoria, como a extensão do molhe do cais comercial em 250 m nos anos 80 , dois reforços de proteção (reforço do troço NATO no início da década de 90 e reforço do cotovelo do molhe no final da década de 90) e a criação do complexo Portas do Mar em 2008, obra de grande destaque nos últimos anos. Na atualidade, o referido porto divide-se nas áreas indicadas na fig. 8.

O cais acostável, no interior do molhe do cais comercial, é constituído por um parque de contentores, armazéns, abastecimento de navios e serviços da alfândega, permitindo o abastecimento de água potável, combustível e gás natural, bem como a carga e descarga de mercadorias. Apresenta uma área de $3800 \mathrm{~m}^{2}$ destinada ao armazenamento de contentores. 0 parque de contentores distribui-se, na grande maioria, na zona do cais fundada a $-10.0 \mathrm{~m} \mathrm{Z.H.} \mathrm{(a} \mathrm{zona} \mathrm{mais} \mathrm{larga} \mathrm{do} \mathrm{cais)} \mathrm{e} \mathrm{o}$ restante encostado ao longo da muralha, desde a zona do cais fundada a $-10.0 \mathrm{~m}$ Z.H. até à zona fundada $\mathrm{a}-12.0 \mathrm{~m}$ Z.H.. O abastecimento dos navios faz-se ao longo de todo o cais, através de treze tomadas de abastecimento de combustíveis líquidos. A receção de gás realiza-se através de uma tomada na zona do cais fundada a $-6.0 \mathrm{~m}$ Z.H. e a de combustíveis líquidos através de uma tomada na zona do cais fundada a $-10.0 \mathrm{~m}$ Z.H.. Encontram-se tomadas de abastecimento de água ao longo de todo o cais (abastecimento público) e ainda treze tanques com capacidade de cerca de $60 t$ de água fornecida através de três bombas (uma na zona do cais fundada a $-10.0 \mathrm{~m}$ Z.H. e duas na zona fundada a $-12.0 \mathrm{~m}$ Z.H..

0 porto de pesca (fig. 8) destina-se à amarração de embarcações de pequeno e médio porte, bem como ao apoio da prática de pesca, quer ao largo, quer na zona das pontes-cais. Na zona de ligação entre o porto 


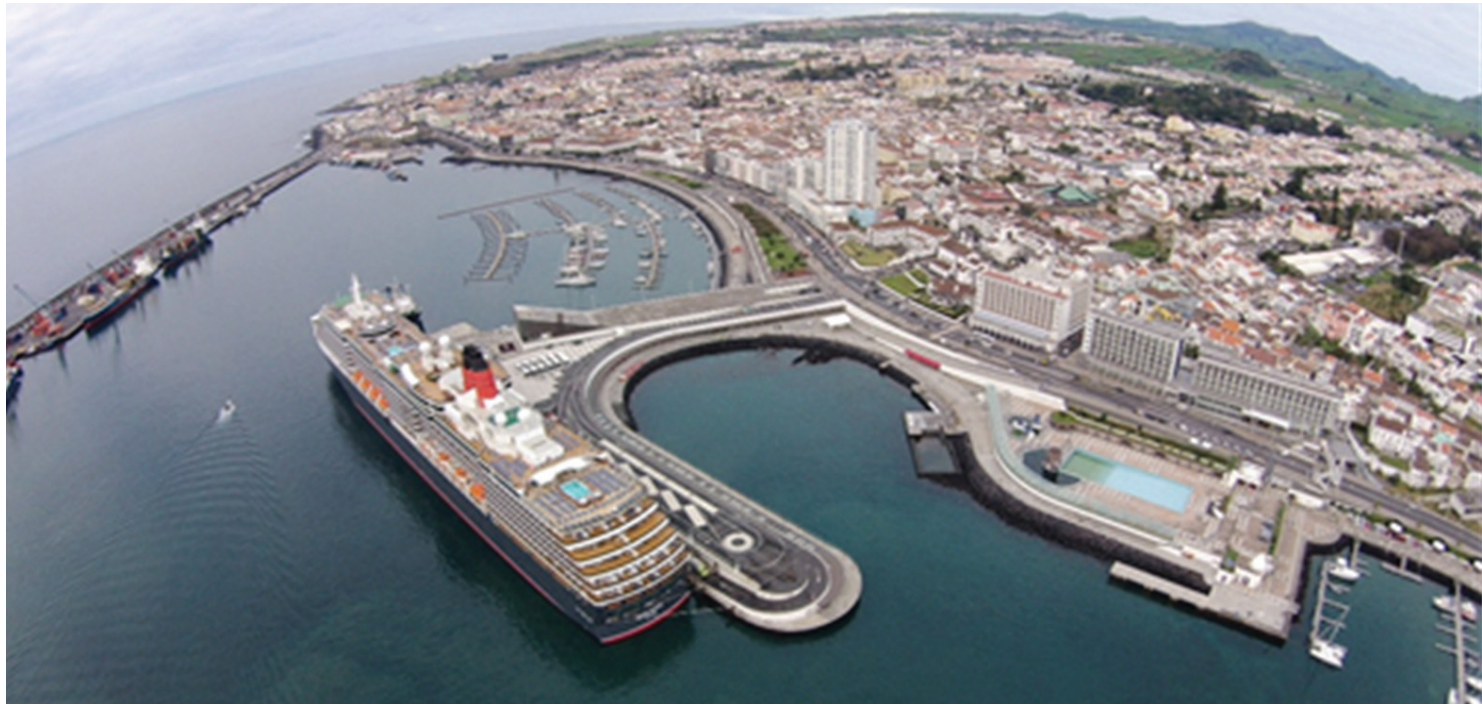

Fig. 6 - Fotografia aérea do porto de Ponta Delgada (https://www.facebook.com/pages/Porto-de-Ponta-Delgada/187997584578504).

Fig. 6 - Aerial view of Ponta Delgada harbour (https://www.facebook.com/pages/Porto-de-Ponta-Delgada/187997584578504).

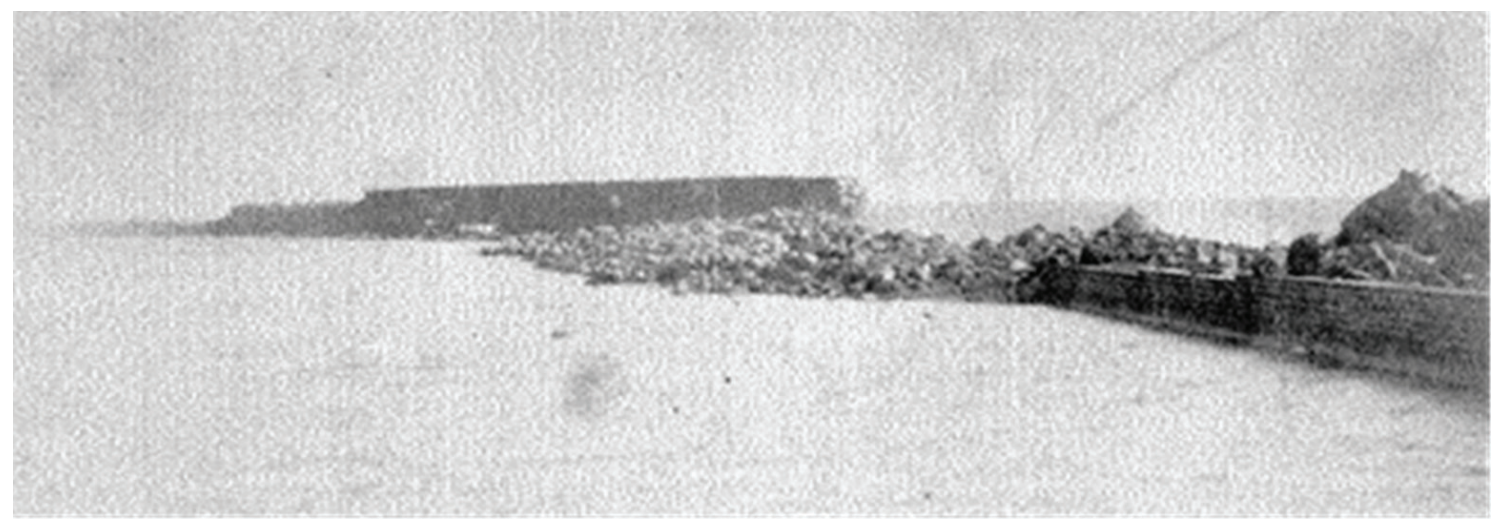

Fig. 7 - Ruínas do molhe principal do porto, dezembro de 1894 (figura disponibilizada pelos Portos dos Açores).

Fig. 7 - Remains of the harbour main breakwater, December, 1894 (Source: figure provided by the Portos dos Açores).

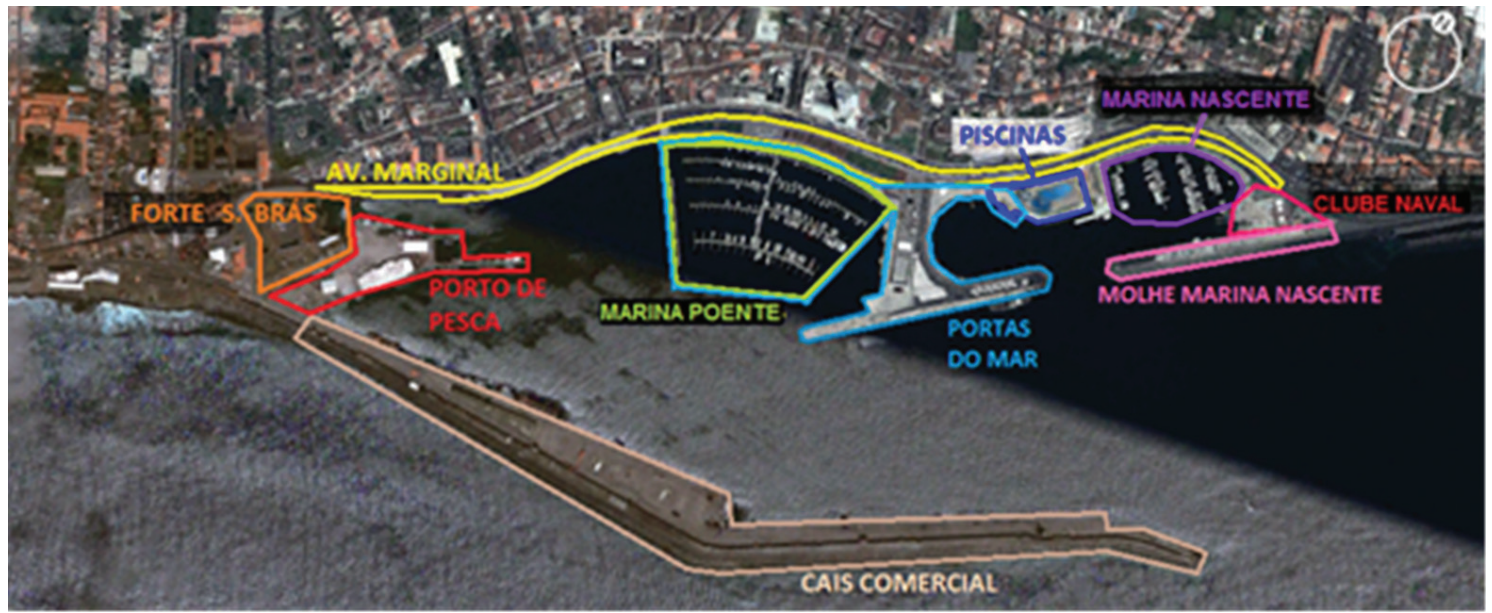

Fig. 8 - Diferentes zonas do porto de Ponta Delgada (J. Rodrigues, 2014).

Fig. 8 - Different areas of Ponta Delgada harbour (J. Rodrigues, 2014). 
de pesca e o cais comercial, encontra-se um local de abastecimento de combustível, o edifício da Lota e um hangar da marinha.

O Forte de S. Brás (fig. 8), também denominado Museu Militar dos Açores desde 2006, representava no séc. XVI a maior fortificação da ilha, sendo agora a única construção militar de São Miguel que não se encontra em ruínas. A sua construção justificou-se pelos constantes ataques de piratas e corsários, atraídos pelas riquezas provenientes da Índia, África e Brasil. Situa-se na zona poente da área em estudo, mantendo uma ligação com o porto de pesca e dando início à marginal.

A Avenida marginal ou Avenida Infante D. Henrique (fig. 8) serve de ligação entre o Forte de S. Brás e o Clube Naval. É uma zona de constante fluxo, quer de peões, quer de viaturas, tornando-se assim prioritário proteger os mesmos da agitação marítima. Em grande parte da extensão da avenida é possível distinguir dois níveis de circulação: um a cotas mais baixas, apenas para peões e ciclistas, onde se encontram apenas dois espaços comerciais, estando protegidos por um pequeno talude de enrocamento; outro, a cotas mais elevadas, bastante mais protegido, onde é possível encontrar pequenos cafés com esplanadas, variados espaços comerciais e grande movimentação de veículos.

Construído em 2008, o complexo Portas do Mar (fig. 8) trata-se de um projeto da autoria do Arquiteto Manuel Salgado com o objetivo de requalificar a frente marítima de Ponta Delgada, garantir um novo polo de atração à maior cidade açoriana e satisfazer a necessidade de aumentar a marina pré-existente. A obra incluiu a nova marina, um terminal de cruzeiros e ferryboats, o Pavilhão do Mar (com anfiteatro ao ar livre, salão polivalente e restaurante), um parque de estacionamento subterrâneo por baixo da Avenida Marginal, com 200 lugares, uma zona de restauração e comércio, uma piscina natural de marés, e ainda um jardim com $10000 \mathrm{~m}^{2}$ ao longo da Avenida Marginal.

A nova marina (fig. 8), ou marina poente surgiu da necessidade de aumentar o número de amarrações de iates em 477 lugares, atingindo agora as 670. Tal como o núcleo da marina nascente, dispõe de plataformas flutuantes para amarração das embarcações. Recentemente (2009), e devido à elevada agitação verificada aquando da existência de ventos de sudoeste, foi colocado um quebra-mar flutuante de proteção à marina do núcleo poente.

A marina nascente (fig. 8), conhecida por marina Pêro de Teive, tem as suas embarcações abrigadas da agitação proveniente do sul por um molhe protegido com um manto de tetrápodos. Situa-se entre a zona das piscinas e o Clube Naval. Tal como no núcleo poente da marina, existe a possibilidade de abastecimento de água, eletricidade e combustível, dispondo ainda de infraestruturas de apoio à navegação de recreio, como balneários, lavandaria, telefones, etc. Permite atracar 140 embarcações em passadiços flutuantes que recorrem a uma rampa varadouro, apesar de pertencer à jurisdição do Clube Naval.

\section{Avaliação das consequências utilizando o AHP}

No caso do porto de Ponta Delgada, foram considerados os indicadores apresentados na fig. 9.

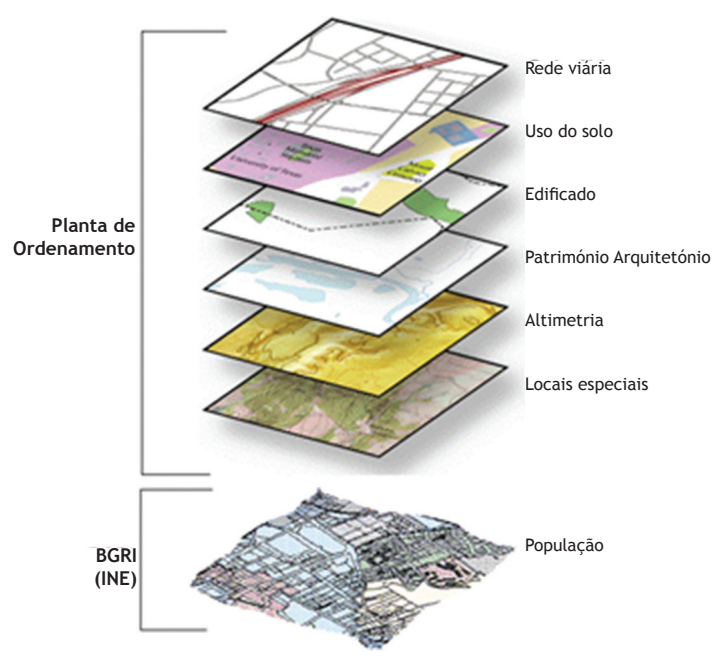

Fig. 9 - Indicadores e fonte de dados para o caso em estudo.

Fig. 9 - Disaster criteria and data sources for the study case.

Os dados que caracterizam os indicadores provieram de diferentes fontes (fig. 9), tanto da BGRI (Base Geográfica de Referenciação de Informação) fornecida pelo INE (Instituto Nacional de Estatística), como a partir do PDM (Plano Diretor Municipal) e do PO (Planta de Ordenamento). Dessas mesmas fontes pode ser retirada diversa informação, desde as cotas de inundação, a cartografia com os diferentes usos do solo, a distribuição dos edifícios e vias de comunicação, a população residente, etc.

De entre a informação disponibilizada, a escolha destes indicadores assenta num conjunto de elementos que os autores consideraram relevantes para caraterizar o local e cujo impacto associado ao fenómeno do galgamento pode ser significativo. Outros indicadores poderão vir a ser considerados após parecer das autoridades locais. No entanto, a metodologia a aplicar em nada difere.

Para os indicadores referidos, consideraram-se os atributos apresentados na TABELA III.

\section{Atribuição de pesos aos indicadores}

Recorrendo à matriz de comparação, construída como indicado na TABELA I, resulta a TABELA IV para o caso de estudo de Ponta Delgada, com base numa consulta feita às autoridades locais. Para obter os pesos relativos a cada 
TABELA III - Indicadores e atributos considerados.

TABLE III - Disaster criteria and attributes considered.

\begin{tabular}{|c|c|}
\hline Indicadores & Atributos \\
\hline \multirow{3}{*}{$\begin{array}{l}\text { Património } \\
\text { Arquitetónico }\end{array}$} & Monumento Regional \\
\hline & Imóvel de interesse público \\
\hline & Imóvel de interesse municipal \\
\hline \multirow{6}{*}{$\begin{array}{l}\text { Locais } \\
\text { Especiais }\end{array}$} & Depósito de sucata \\
\hline & Lixeira \\
\hline & Aterro sanitário \\
\hline & ETAR \\
\hline & Depósito de combustível \\
\hline & Instalações militares \\
\hline Edificado & Edifícios (de qualquer natureza) \\
\hline Altimetria & $\begin{array}{c}\text { Cotas variam entre } 0 \mathrm{~m} \text { e } 874 \mathrm{~m} \\
\left(\mathrm{NMM}^{*}\right)\end{array}$ \\
\hline \multirow{3}{*}{ Rede Viária } & $\begin{array}{c}\text { Estradas regionais principais e } \\
\text { secundárias }\end{array}$ \\
\hline & Estradas e caminhos municipais \\
\hline & Eixos urbanos estruturantes \\
\hline \multirow{3}{*}{ Uso do Solo } & Solos urbanizados \\
\hline & Solos naturais \\
\hline & Solos com uso especial \\
\hline População & População residente \\
\hline
\end{tabular}

*NMM=Nível Médio das águas do Mar

indicador é necessário normalizar esta matriz. Para tal, para uma dada coluna, divide-se o valor de cada coeficiente pela soma de todos os coeficientes dessa coluna (TABELA V).

O valor que representa o peso de cada indicador é o vetor próprio e R. V. Vargas (2010) propõe como valor aproximado para este vetor a média aritmética dos valores obtidos em cada linha da matriz normalizada (TABELA VI).

Para validar a consistência dos pesos atribuídos é calculado um índice de inconsistência $\lambda_{\text {Max }}=7.65$ (equação 1), um índice de consistência $(\mathrm{Cl}$, equação 2) e uma taxa de consistência (CR, equação 3) (TABELA VII), para o valor de $\mathrm{RI}=1.32$, uma vez que foram considerados 7 indicadores (TABELA II).
TABELA VII - Índice de consistência (Cl) e taxa de consistência (CR) do caso de estudo.

$T_{A B L E}$ VII - Consistency index (CI) and consistency rate (CR) for the case study.

\begin{tabular}{|c|c|}
\hline $\mathrm{CI}$ & 0.11 \\
\hline $\mathrm{CR}$ & 0.08 \\
\hline
\end{tabular}

Segundo T. L. Saaty (2005) e como referido anteriormente, a matriz pode então considerar-se consistente, uma vez que a taxa de consistência (CR) se revela menor do que 0.1 (equação 3). Assim, os pesos atribuídos aos indicadores podem ser utilizados na avaliação das consequências de ocorrência de galgamentos e respetivo mapa.

\section{Distribuição de pesos dos atributos}

Cada um destes indicadores foi integrado num SIG sob a forma de camada (layer), cada uma caraterizada por um conjunto de atributos. Neste caso, a classificação desses atributos não justificou a aplicação do AHP, pelo que se fizeram corresponder arbitrariamente a cada um diferentes pesos numa escala crescente de importância que varia entre 1 e 9 .

A TABELA VIII mostra os diferentes pesos atribuídos a cada indicador e atributo. Torna-se relevante indicar que os pesos atribuídos aos indicadores foram definidos após contacto com as autoridades locais (Câmara Municipal de Ponta Delgada), sendo que a aplicação do AHP serviu para analisar a consistência dessa mesma distribuição. Em geral, os pesos obtidos pelo AHP (TABELA VI) validam os pesos atribuídos aos vários indicadores segundo parecer da Câmara Municipal de Ponta Delgada, já que, como se pode ver na TABELA VIII, os valores têm sensivelmente a mesma ordem de grandeza.

Para os atributos, apesar de possível a aplicação do AHP, essa atribuição dos pesos foi feita de forma arbitrária numa escala de 1 a 9 , em que 1 corresponde ao atributo menos importante e 9 ao mais importante (P. Poseiro et al., 2013b). Esta etapa carece ainda de um parecer das autoridades locais.

TABela IV - Matriz comparativa do grupo de indicadores selecionados.

$T_{A B L E} I V$ - Comparison matrix for the selected disaster criteria.

\begin{tabular}{|l|l|c|c|c|c|c|c|c|}
\hline \multicolumn{1}{|c|}{ Indicador } & A & B & C & D & E & F & G \\
\hline A & Património Arquitetónico & 1 & $1 / 2$ & 3 & 7 & 7 & 7 & $1 / 2$ \\
\hline B & Locais Especiais & 2 & 1 & 5 & 9 & 7 & 7 & $1 / 2$ \\
\hline C & Edificado & $1 / 3$ & $1 / 5$ & 1 & 5 & 5 & 5 & $1 / 4$ \\
\hline D & Altimetria & $1 / 7$ & $1 / 9$ & $1 / 5$ & 1 & $1 / 3$ & $1 / 3$ & $1 / 9$ \\
\hline E & Rede Viária & $1 / 7$ & $1 / 7$ & $1 / 5$ & 3 & 1 & 1 & $1 / 9$ \\
\hline F & Uso do Solo & $1 / 7$ & $1 / 7$ & $1 / 5$ & 3 & 1 & 1 & $1 / 9$ \\
\hline G & População & 2 & 2 & 4 & 9 & 9 & 9 & 1 \\
\hline & & & 4.10 & 13.60 & 37.00 & 30.33 & 30.33 & 2.58 \\
\hline
\end{tabular}


TABELA V - Matriz normalizada.

TABLE V - Normalized matrix.

\begin{tabular}{|l|l|c|c|c|c|c|c|c|}
\hline \multicolumn{1}{|c|}{ Indicador } & A & B & C & D & E & F & G \\
\hline A & Património Arquitetónico & 0.174 & 0.122 & 0.221 & 0.189 & 0.231 & 0.231 & 0.194 \\
\hline B & Locais especiais & 0.347 & 0.244 & 0.368 & 0.243 & 0.231 & 0.231 & 0.194 \\
\hline C & Edificado & 0.058 & 0.049 & 0.074 & 0.135 & 0.165 & 0.165 & 0.097 \\
\hline D & Altimetria & 0.025 & 0.027 & 0.015 & 0.027 & 0.011 & 0.011 & 0.043 \\
\hline E & Rede Viária & 0.025 & 0.035 & 0.015 & 0.081 & 0.033 & 0.033 & 0.043 \\
\hline F & Uso do solo & 0.025 & 0.035 & 0.015 & 0.081 & 0.033 & 0.033 & 0.043 \\
\hline G & População & 0.347 & 0.488 & 0.294 & 0.243 & 0.297 & 0.297 & 0.387 \\
\hline
\end{tabular}

TABELA VI - Cálculo do vetor próprio. TABLE VI - Calculation of the Eigenvector.

\begin{tabular}{|c|c|c|}
\hline Indicador & Peso & Peso (\%) \\
\hline Património Arquitetónico & 0.194 & 19.44 \\
\hline Locais Especiais & 0.265 & 26.53 \\
\hline Edificado & 0.106 & 10.60 \\
\hline Altimetria & 0.023 & 2.27 \\
\hline Rede Viária & 0.038 & 3.78 \\
\hline Uso do solo & 0.038 & 3.78 \\
\hline População & 0.336 & 33.62 \\
\hline$\Sigma$ & & 100.00 \\
\hline
\end{tabular}

Para trabalhar os dados indicados na TABELA VIII recorreu-se ao software ArcGIS ${ }^{T M}$, tendo sido criado um modelo com a ferramenta ModelBuilder com todos os passos necessários até ao resultado final (J. Rodrigues, 2014; J. Rodrigues et al., 2014).

Relativamente ao indicador 'Uso do Solo', achou-se relevante considerar três escalas de diferentes atributos, com distintas escalas de importância. Ao atributo 'solos urbanizados' concedeu-se o peso igual a 5 por se considerar o menos relevante dos três; no atributo 'solos naturais', o peso de 8; e para o atributo 'solos com uso especial', considerou-se um peso de 9 , que traduz a maior importância deste atributo.

Em relação ao 'Património Arquitetónico', fig. 10a, reuniu-se numa só layer os dados considerados merecedores da mesma classificação (como por exemplo, os 'imóveis classificados ou em vias de classificação' e os 'imóveis com valor arquitetónico') e classificaramse esses imóveis de 1 a 9 consoante sejam de pouco interesse ou de muito interesse. Uma vez que a fonte de dados fornecida se encontrava representada sob a forma de pontos, e uma vez que não se conheciam, de entre os edifícios, qual a área correspondente ao património arquitetónico, utilizou-se a densidade de Kernel para dar representatividade a este indicador.
Quanto ao 'Edificado', fig. 10b, que considera as construções de qualquer natureza, a classificação é 1 para os locais onde não há edifícios (menos grave) e 9 para locais onde os há (mais grave).

Para a 'Altimetria' (fig. 11a) representa-se, através das curvas de nível, um modelo tridimensional indicativo das cotas de cada ponto. Assim, obteve-se uma layer cujo nível de gravidade diminui com o aumento da cota do terreno. No caso da layer da 'Rede Viária' (fig. 11b) aplicou-se um filtro de $15 \mathrm{~m}$ de largura de modo a que as vias tenham melhor representação no mapa. Assim, as vias têm uma classificação de 9 , pelo que o restante se classifica com grau 1.

No que diz respeito ao indicador 'População', nos dados dos Censos 2011 fornecidos pelo INE foi possível aceder, ao nível da subsecção estatística, à informação da população residente na cidade de Ponta Delgada. Foi então estabelecida no ArcGIS'M uma correspondência (Join)

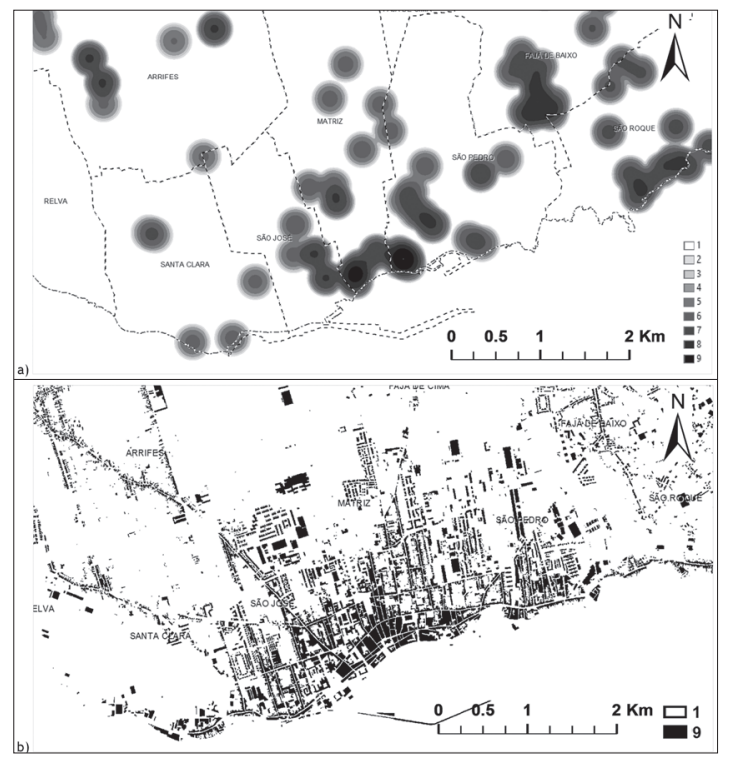

Fig. 10 - Layers representativas do Património Arquitetónico com aplicação da ferramenta Kernel Density (a) e do Edificado (b).

Fig. 10 - Layers of the Architectural Heritage with the application of the tool Kernel Density (a) and of the Buildings Areas (b). 


\section{territorium 24}

TABELA VIII - Pesos atribuídos aos vários indicadores e atributos considerados.

TABLE VIII - Weights assigned to the different disaster criteria and attributes.

\begin{tabular}{|c|c|}
\hline $\begin{array}{c}\text { INDICADORES } \\
\text { Classificação segundo o AHP }\end{array}$ & $\begin{array}{c}\text { ATRIBUTOS (peso) } \\
\text { Classificação arbitrária de } 1 \text { a } 9\end{array}$ \\
\hline \multirow{3}{*}{$\begin{array}{l}\text { Património Arquitetónico } \\
\qquad 15 \%^{1}\left(19.44 \%^{2}\right)\end{array}$} & Monumento regional (9) \\
\hline & Imóvel de interesse público (9) \\
\hline & Imóvel de interesse municipal (9) \\
\hline \multirow{6}{*}{$\begin{array}{l}\text { Locais Especiais } \\
40 \%^{1}\left(26.53 \%^{2}\right)\end{array}$} & Depósito de sucata (7) \\
\hline & Lixeira (7) \\
\hline & Aterro sanitário (7) \\
\hline & ETAR (9) \\
\hline & Depósito de combustível (9) \\
\hline & Instalações militares (9) \\
\hline $\begin{array}{c}\text { Edificado } \\
10 \%{ }^{1}\left(10.60 \%^{2}\right)\end{array}$ & Edifícios (de qualquer natureza) (9) \\
\hline \multirow{9}{*}{$\begin{array}{l}\text { Altimetria } \\
1 \%^{1}\left(2.27 \%^{2}\right)\end{array}$} & $0-34$ m (9) \\
\hline & $34-75$ m (8) \\
\hline & $75-128 m(7)$ \\
\hline & $128-194 m(6)$ \\
\hline & $194-276$ m (5) \\
\hline & $276-380$ m (4) \\
\hline & $380-508$ m (3) \\
\hline & $508-670 m(2)$ \\
\hline & $670-874$ m (1) \\
\hline \multirow{3}{*}{$\begin{array}{l}\text { Rede Viária } \\
5 \%^{1}\left(3.78 \%^{2}\right)\end{array}$} & Estradas regionais principais e secundárias (9) \\
\hline & Estradas e caminhos municipais (9) \\
\hline & Eixos urbanos estruturantes (9) \\
\hline \multirow{3}{*}{$\begin{array}{l}\text { Uso do Solo } \\
4 \%^{1}\left(3.78 \%^{2}\right)\end{array}$} & Solos urbanizados (5) \\
\hline & Solos naturais $(8)$ \\
\hline & Solos com uso especial (9) \\
\hline $\begin{array}{c}\text { População } \\
25 \%^{1}\left(33.62 \%^{2}\right)\end{array}$ & População residente (9) \\
\hline
\end{tabular}

${ }^{1}$ Valores que resultam do parecer da Câmara Municipal de Ponta Delgada.

2 Valores obtidos pelo AHP, TABELA VI.

entre o shapefile com os polígonos correspondentes a cada subsecção estatística e a tabela que contém a informação dos Censos 2011 correspondente, neste caso específico, à população residente. Uma vez que esses resultados dizem respeito à população residente em cada uma dessas subsecções (fig. 12a), foi necessário calcular a distribuição da população por $\mathrm{m}^{2}$ (fig. 12b). Desta forma, criou-se um novo atributo resultante da divisão entre a população residente em cada subsecção pela área da mesma.

Elaboração do mapa de consequências com o software ArCGIS 10.1TM

Finalmente, tal como referido em P. Poseiro et al. (2013b), utilizou-se o fluxograma desenvolvido no ModelBuilder, obtendo-se, por fim, o seguinte mapa de consequências (fig. 13) que representa, numa escala de 1 a 5 , as áreas com diferentes níveis de consequências, em que 1 representa áreas com consequências insignificantes e 5 representa áreas com as consequências mais sérias.

\section{Conclusões}

O presente trabalho ilustra a análise das consequências de ocorrência de galgamentos no porto de Ponta Delgada através da aplicação do Processo de Análise Hierárquica (AHP) e de ferramentas SIG, i.e. tendo em conta a distribuição espacial de vários indicadores/atributos que caracterizam a zona de estudo. Pode verificar-se que a área que diz respeito ao centro de Ponta Delgada é a que apresenta maior grau de consequências, uma 


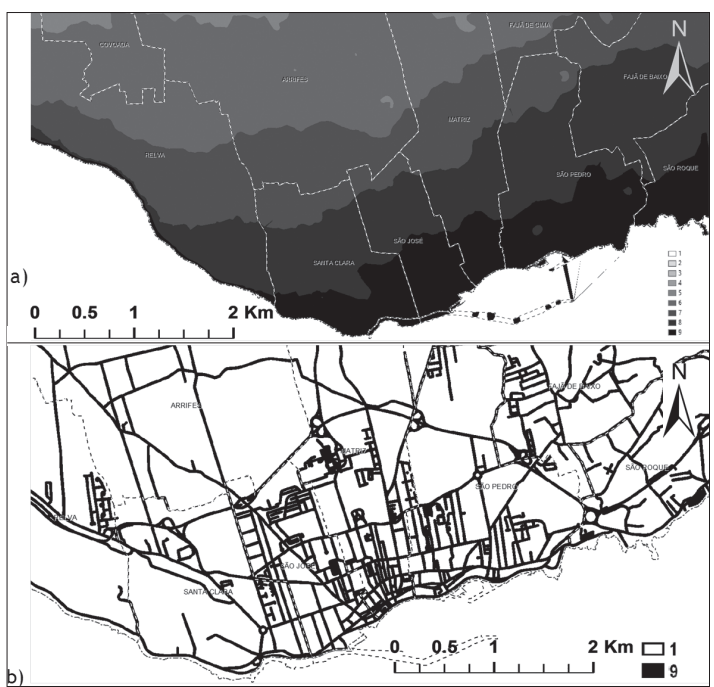

Fig. 11 - Layers representativas da Altimetria (a) e da Rede Viária (b).

Fig. 11 - Layers of the Altimetry (a) and of the Road Network (b).

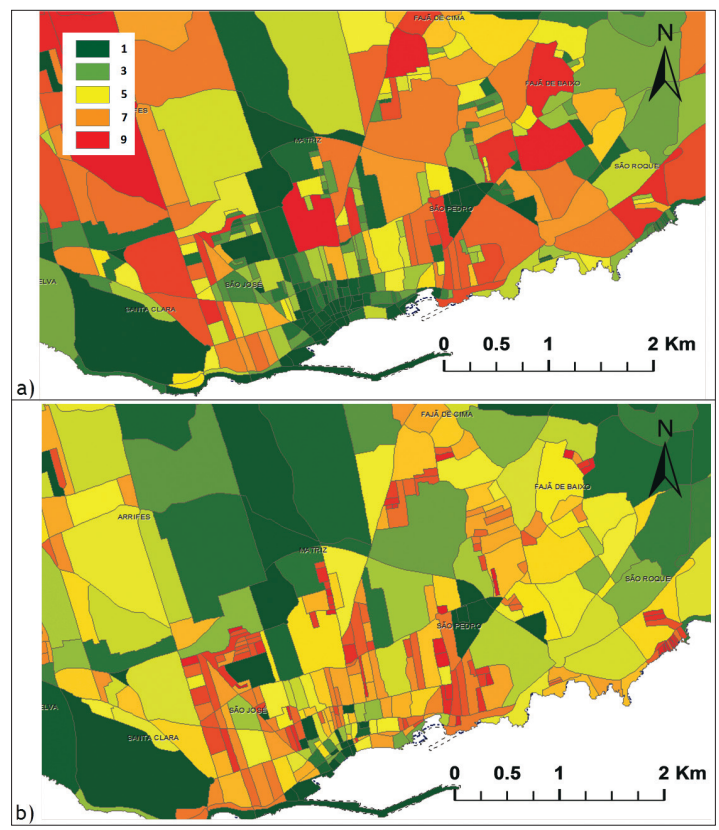

Fig. 12 - Layers representativas da distribuição da população por área (subsecção estatística) (a) e da distribuição da população/m² (b).

Fig. 12 - Layers of the population distribution by area (statistical subsection) (a) and of the population distribution $/ \mathrm{m}^{2}(b)$.

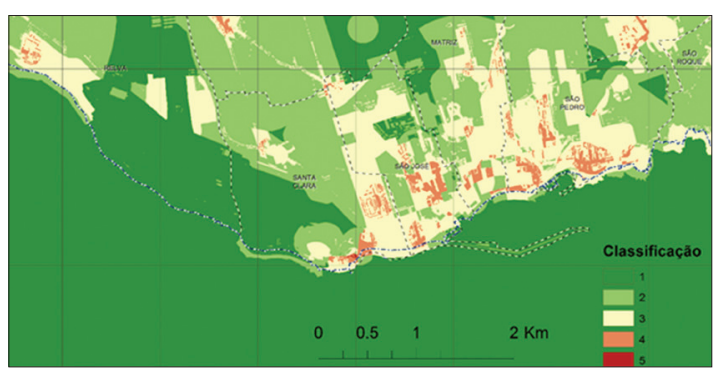

Fig. 13 - Mapa de consequências resultante da aplicação do AHP.

Fig. 13 - Consequences map obtained using AHP. vez que é um local de concentração da população, de infraestruturas, de grande parte do património arquitetónico, etc.

A aplicação do método de avaliação das consequências de galgamentos baseado no AHP e em ferramentas SIG mostrou-se bastante mais vantajoso do que o método simplista já utilizado anteriormente por P. Poseiro et al. (2013a), no qual se avaliou global e qualitativamente as consequências, se teve em conta, apenas de forma indireta, indicadores que representam a distribuição espacial ou a existência de infraestruturas, e não houve a preocupação de atribuir pesos a esses indicadores que permitissem que o mapa de consequências tivesse em conta simultaneamente todos os indicadores. 0 AHP permite obter resultados baseados numa análise espacial dos indicadores que caraterizam o local, no que diz respeito à sua importância relativa e mostrou ser um método multicritério simples de aplicar e que ajuda a definir o peso a atribuir a cada indicador.

A utilização desta metodologia vem melhorar a caraterização espacial dos elementos expostos a diversos perigos. Neste caso estes elementos servirão, juntamente com a delimitação da área inundável pelo galgamento, para elaborar uma carta de risco de galgamento para o local.

No futuro, será preciso melhorar os pesos a atribuir a cada indicador/atributo, de acordo com informações fornecidas pelas autoridades responsáveis. Caso se considere necessário, pode expandir-se a utilização do AHP aos atributos.

\section{Agradecimentos}

Os autores agradecem o financiamento da FCT através do projeto HIDRALERTA - PTDC/AAC-AMB/120702/2010. Agradecem também à CONSULMAR (Eng. Lucília Luís), aos Portos dos Açores (Sr. Hernâni Vicente e Eng ${ }^{\circ}$ Francisco Silva), à Camara Municipal de Ponta Delgada (Sr. João Moniz), à Azorina (Eng. Conceição Rodrigues), à Universidade dos Açores (Prof. Eduardo de Azevedo, Dr. Francisco Reis e Dra. Anabela Simões) e ao Instituto Hidrográfico (Sr. Nuno Pereira da Costa), as informações prestadas e a disponibilização dos dados necessários à realização deste trabalho.

\section{Bibliografia}

Antunes, O. (2012). Análise Multicritério em SIG para Determinação de um Índice Espacializado de Pressão Antrópica Litoral. Casos de Espinho, Caparica e Faro. (Tese de Mestrado), Faculdade de Ciências Sociais e Humanas, Universidade Nova de Lisboa.

Aragonés-Beltrás, P., García-Melón, M., Estruch-Guitart, V. (2015). Analysis of the participation of stakeholders 
in environmental management based on AHP: application to a Spanish natural park. International Journal of the Analytic Hierarchy Process, 7, 1 (2015).

Bhushan, N., Kanwal, R. (2004). Strategic Decision Making: Applying the Analytic Hierarchy Process. Springer-Verlag, New York.

Carver, S. (1991). Integrating multi-criteria evaluation with geographical information systems. International Journal of Geographical Information Systems, 5, 3, 321-339.

Craveiro, J. L., Antunes, O., Freire, P., Oliveira, F., Almeida, I. D., Sancho, F. (2012). Comunidades urbanas na orla costeira: a metodologia multicritério AHP (Analytic Hierarchy Process) para a construção de um índice de vulnerabilidade social face à ação marítima. Atas do $2^{\circ}$ Congresso Ibero Americano de Responsabilidade Social, 25 a 27 de outubro, ISEG, Lisboa, 8p.

Freitas, M. J., Craveiro, J. L. (2015). Report 1 of Workshop 1 of the Stakeholders Panel. LIFE/ HYMEMB, Tailoring Hybrid Membrane Processes for Sustainable Drinking Water Production [LIFE12 ENV/ PT/001154]. Rep.1, t.B5, 31st May 2015.

Greene, R., Devillers, R., Luther, J., Eddy, B. (2011). GISBased Multiple-Criteria Decision Analysis. Geography Compass, 5/6, 412-432.

Malczewski, J. (2006). GIS-based multicriteria decision analysis: a survey of the literature. International Journal of Geographical Information Science, 20, 7, 703-726.

Pereira, D. M. F. (2013). Avaliação do Risco de Galgamento de Estruturas Portuárias: O Caso do Porto de Ponta Delgada (Açores, Portugal). (Dissertação de Mestrado) Engenharia Civil, Universidade da Madeira, Funchal.

Poseiro, P., Fortes, C. J. E. M., Reis, M. T., Santos, J. A., Simões, A., Rodrigues, C., Azevedo, E. (2013a). A methodology for overtopping risk assessment in port areas: Application to the Port of Praia da Vitória (Azores, Portugal). Proc. SCACR 2013 $6^{\text {th }}$ International Conference on Applied Coastal Research, LNEC, 4 a 7 de junho.
Poseiro, P., Fortes, C. J. E. M., Santos, J. A., Reis, M. T., Craveiro, J. (2013b). Aplicação do processo de análise hierárquica (AHP) à análise das consequências de ocorrência de galgamentos. 0 caso da baía da Praia da Vitória. Proc. $8^{a_{s}}$ Jornadas Portuguesas de Engenharia Costeira e Portuária, LNEC, 10 e 11 de outubro.

Rodrigues, J. (2014). Avaliação do Risco e Aplicação do Processo de Análise Hierárquica (AHP) na Avaliação das Consequências de Galgamento em Zonas Costeiras e Portuárias. Aplicação ao Porto de Ponta Delgada, Açores. Dissertação de Mestrado (Engenharia Civil), Faculdade de Engenharia, Universidade do Porto.

Rodrigues, J., Poseiro, P., Reis, M. T., Fortes, C. J, Pinto, F. T. (2014). Aplicação do processo de análise hierárquica (AHP) na avaliação das consequências de galgamento em zonas portuárias - caso de Ponta Delgada, Açores. III Congresso Internacional; I Simpósio Ibero-Americano; VIII Encontro Nacional de Riscos; 5-7 de novembro, Departamento de Geografia da Universidade do Minho, Guimarães, 2014 - Multidimensão e Territórios de Risco. Coimbra: [s.n.], pp. 421-426. ISBN 978-989-96253-3-4 (PDF). DOI: http://dx.doi.org/10.14195/978-989-96253-3-4_71.

Saaty, T. (1980). The Analytic Hierarchy Process. McGraw Hill: New York.

Saaty, T. L. (2005). Theory and Applications of the Analytic Network Process: Decision Making with Benefits, Opportunities, Costs, and Risks. RWS Publications, Pittsburgh.

Silva, D. M. F. (2012). Avaliação do Galgamento de Estruturas Portuárias. (Dissertação de Mestrado), Engenharia Civil, Faculdade de Ciências e Tecnologia, Universidade de Coimbra.

Silva, D. M. F., Fortes, C. J. E. M., Reis, M. T., Antunes do Carmo, J. S., Simões, A., Rodrigues, C. (2012). Avaliação do galgamento de estruturas portuárias: Porto de Ponta Delgada. Recursos Hídricos, APRH, 33, 2, 37-51.

Vargas, R. V. (2010). Utilizando a programação multicritério (Analytic Hierarchy Process - AHP) para selecionar e priorizar projetos na gestão de portfólio. PMI Global Congress 2010. 